\title{
Relationship among Influential Factors of Entrepreneurial Intention in Terms of Gender: Case of Postgraduate Students in Malaysia
}

\author{
${ }^{*}$ Omid Yaghmaei \\ 2Iman Ghasemi \\ ${ }^{3}$ Saman Assadian \\ $1^{*}$ International Business School, Universiti Teknologi Malaysia (UTM), International Campus, Kuala Lumpur, Malaysia \\ ${ }^{2}$ Faculty of Management, Universiti Teknologi Malaysia (UTM), International Campus, Kuala Lumpur, Malaysia \\ ${ }^{3}$ Business Training Center of Khorasan Razavi, University of Applied Science and Technology, Iran \\ Correspondence: Omid Yaghmaei (email: oyaghmaei@gmail.com)
}

\section{Doi:10.5901/mjss.2015.v6n3p195}

\begin{abstract}
In the last two decades, entrepreneurship has become an important concept, not only in economy, but also in politics, education and research. Studies have shown that entrepreneurship is a promoter for economic development so that entrepreneurial intention is gaining more importance in developing countries like Malaysia. This study aims to find out the relationship among influential factors of entrepreneurial intention (previous experience, education, attitude, subjective norms, and behavioral control) in terms of gender. Data collection was conducted in Universiti Teknologi Malaysia (UTM) in June 2014. A total of 380 questionnaires were distributed among 187 male and 193 female postgraduate students. The results showed that there was no significant difference between females and males in previous experience, education, attitude, subjective norms, behavioral control and entrepreneurial intention. Therefore, there was no significant difference in entrepreneurial intention between males and females.
\end{abstract}

Keywords: Gender, Entrepreneurship, Entrepreneurial Intention, Previous Experience, Education, Attitude, Subjective Norms, Behavioral Control.

\section{Introduction}

Entrepreneurship has been recognized as a promoter for economic development (Baughn, Cao, Le, Lim, \& Neupert, 2006). Therefore, in the past few years, the number of universities offering entrepreneurship courses has increased dramatically which indicates the increasing importance of entrepreneurship in social, economic and political dimensions.

Entrepreneurship is gaining more importance in Malaysia. Studies show that entrepreneurial activities support the economy of Malaysia; therefore, Malaysian governors have allocated special funding facilities for interested people. The focus of Malaysia on entrepreneurship moved to a higher level when the Ministry of Entrepreneur Development was established in 1995. Malaysian government has put entrepreneurship as a key factor in economic growth and a mean to create new jobs and reduce the rate of unemployment.

In the past few years, more graduate students have shown interest in the outcomes of entrepreneurship such as independence and satisfaction. In a study conducted in Ireland, almost half of the participated students mentioned their goal to become self-employed and open their own business (Hart \& Harrison, 1992). In another study in the U.K., again almost half of the students expressed their intention to become self-employed (Ismail, et al., 2009). These findings show significant increase in the students' intention to run their own business, compared to the previous decade. For example, in a study conducted by Brenner, Pringle and Greenhaus (1991), it was found that only $5 \%$ of the participants were willing to start their own business.

In the global dimension, entrepreneurship is a rather new concept. Therefore, the number of empirical studies in this field is limited in certain areas (Lorz, Müller \& Volery, 2011). Despite the numerous numbers of studies on entrepreneurial intention, there is a questionable issue in determining the differences in entrepreneurial intention between males and females. This study aims to investigate whether there is a significant difference in entrepreneurial intention of postgraduate students in Malaysia in terms of gender or not. 


\section{Literature Review}

According to the theory of social learning, different socialization experiences and social expectations of women and men result in diverse work preferences or motivations. Based on the arguments of Bandura (1986), gender development is affected by various factors such as occupational systems, educational practices, media, and peers. Bandura (1986) explained the difference between the socialization of men and women. Women might score lower self-efficacy, be less confident in their abilities, lack powerful personal efficacy expectations regarding various careers which are related to behaviors, and thus might not achieve their complete career potential due to their different socialization experiences (Chen, et al., 1998). Moreover, sex-role socialization experiences instruct and inform young girls about the gender roles that are suitable for them and those that are not. Studies on gender stereotyping indicate the typical association of masculine characteristics with entrepreneurship. These stereotypical views have adverse impacts on the development and entry of women in entrepreneurship; whereas, a higher entrepreneurship performance is demonstrated by men (Gupta et al., 2009).

The impacts of gender on entrepreneurial intentions are expected to be more strongly reflected in some contexts such as Saudi Arabia. The socialization experiences of young women are formed by strict expectations imposed by gender roles within the Muslim societies of the Middle East. The first and foremost roles expected of women are to be homemakers, mothers, and wives, whereas men are expected to protect their families. The power of men does not only rise from economic justifications like their 'bread winner' identity; it is rather embedded in their politics, society, religion, and culture. The gender ideology that has been promoted in the political culture of Saudi elevates sex segregation and idealizes the domesticity of women (Bandura, 1986). Strict segregation between the socializing places and workplaces of men and women has been instituted since 1960's with particular laws. Although women of Saudi have increasing access to the right to work and study, there are serious restrictions in their becoming involved with political life. They also lack an opportunity of properly entering and participating in the economic life. Moreover, enough role models of prosperous and successful female entrepreneurs have not been provided by the new phenomenon of the entrepreneurship of women in order for the pursuit of entrepreneurial initiatives as desirable and legitimate career path to be reinforced. One of the members of Saudi Management Association, from the Women's branch revealed in an interview in 2006 that "this issue does not concern a great number of women; some even believe the recent changes to be wrong while others merely do not wish for women to be visible or to change"(Chen, et al., 1998). Subsequently, entrepreneurship might be considered by the female Saudi youths to be an improper gender role; therefore, they are less motivated to engage in entrepreneurial careers. Moreover, women might not be certain about possessing the skills and qualifications necessary in a successful pursue of entrepreneurial initiatives. Even in cases where they are greatly confident about their entrepreneurial abilities, they might be uncertain about whether their business receives social recognition and support or not (Gupta, et al., 2009).

\section{Methodology}

\subsection{Participants}

The participants were chosen from postgraduate students in UTM, Malaysia during 2014. The sample for the study $(n=380)$ consisted of 187 males and 193 females who were in their final year of study and were considered appropriate for a decision in entrepreneurship. The participants were asked to provide the researcher with their demographic information including gender, age, faculty as well as major. Table 1 shows the respondents' demographic backgrounds.

Table 1: Summary of Participants' Socio-demographic Characteristics

\begin{tabular}{ccc}
\hline & Frequency & Percent \\
\hline Gender & 187 & \\
Male & 193 & 49.2 \\
Female & & 50.8 \\
Age & 80 & \\
22-27 years old & 184 & 21.1 \\
27-32 years old & 41 & 48.4 \\
32-37 years old & 75 & 10.8 \\
More than 37 years old & & 19.7 \\
\hline
\end{tabular}




\begin{tabular}{ccc}
\hline Faculty & 250 & 67.9 \\
IBS & 14 & 3.8 \\
MJIIT & 58 & 15.8 \\
Engineering & 32 & 8.7 \\
Psychology & 14 & 3.8 \\
Economy & 16 & 7.8 \\
Major & 10 & 2.6 \\
IT & 265 & 69.7 \\
MBA & 59 & 15.5 \\
Engineering & 40 & 10.5 \\
Psychology & 6 & 1.6 \\
Economics & & \\
\hline
\end{tabular}

\subsection{Procedure}

A total of 380 questionnaires were distributed among the UTM postgraduate students. This was normally scheduled after classes to avoid interruption of the participating students' learning program. Before completion of the questionnaires, the researcher explained the purpose of the study for the participants. The researcher also indicated that there were no preferred responses. The respondents then signed the consent forms. Key concepts including entrepreneurship and small business enterprises were explained to ensure a common understanding of the terms by the researcher and the respondents. Entrepreneurship was explained as creation of a business based on Gartner (1985), but also ownership of small enterprises not necessarily created by the respondent. Small businesses were described to include micro, and informal enterprises including kiosks, and hawking. This definition was used, as the purpose of the study was not to capture innovation, but intention towards entrepreneurship.

The respondents answered categorical and multiple choice questions on the background and demographic variables, and gave responses to Likert-scale questions on a scale of 1 to 5, 'strongly agree' to 'strongly disagree,' covering perceptions of personal and social desirability, and feasibility of entrepreneurship. The exercise took between 20-30 minutes. To safeguard anonymity and confidentiality of the responses, the researcher collected the questionnaires and the signed consent forms separately. The respondents retained copies of the signed consent forms for their records. The completed questionnaires were well secured against possible interference, damage, or deterioration.

The completed questionnaires were all given unique identifiers ranging from 1-380, for ease of reference, and to safeguard data integrity. The different responses were then coded. The nominal gender variable, male, was coded (1) and female (2). Inapplicable questions, such as whether the experience was positive/negative where the respondent had indicated that he/she had never started business, were coded (9) and missing responses (99). The responses to the Likert-scale questions were coded from 1 to 5 for 'strongly disagree' to 'strongly agree'. A database was then created for all the variables, in SPSS, showing what kind of variable the response was: numerical or nominal, the size of the variable, and what the codes meant. The data were then keyed into the database. Thereafter, an exploratory data analysis was run to check for the obvious errors. Necessary corrections were made.

\subsection{Data Analysis Method}

The data analysis included simple descriptive statistics, correlation and t-test. The t-test was used to compare means, whether the scores for males and females are different (Kothari, 2004). Simple descriptive statistics including frequencies and percentages were used to analyze the respondents' background and demographic data. Mean scores and standard deviation were calculated for the Likert-scale questions to develop a participant profile.

\section{Results}

To construct the independent and dependent variables, the means of items related to each variable in the questionnaire have been calculated. Table 2 presents some descriptive statistics of the variables. As can be seen, Skewness and Kurtosis values for all research variables are less than 1 . We can therefore accept that the distribution of variables does not differ much from normal distribution and being normal theory about those variables is true. 
Table 2: Descriptive Statistics of Research Variables

\begin{tabular}{|c|c|c|c|c|c|c|c|c|c|}
\hline & \multirow{2}{*}{$\mathbf{N}$} & \multirow{2}{*}{ Min } & \multirow{2}{*}{ Max } & \multirow{2}{*}{ Mean } & \multirow{2}{*}{ SD } & \multicolumn{2}{|c|}{ Skewness } & \multicolumn{2}{|c|}{ Kurtosis } \\
\hline & & & & & & Statistic & Std. Error & Statistic & Std. Error \\
\hline Previous Experience & 380 & 0.0 & 2.7 & 1.4 & 0.6 & -0.2 & 0.1 & -0.6 & 0.2 \\
\hline Education & 150 & 1.4 & 4.5 & 3.2 & 0.6 & -0.7 & 0.2 & 0.3 & 0.4 \\
\hline Attitude & 200 & 1.2 & 5.0 & 3.9 & 0.8 & -0.9 & 0.2 & 0.8 & 0.3 \\
\hline Subjective Norms & 378 & 1.0 & 5.0 & 3.6 & 0.9 & -0.9 & 0.1 & 0.6 & 0.3 \\
\hline Behavioral Control & 376 & 1.3 & 5.0 & 3.8 & 0.7 & -0.7 & 0.1 & 0.7 & 0.3 \\
\hline Entrepreneurial Intention & 295 & 0.9 & 4.4 & 3.0 & 0.7 & -0.5 & 0.1 & 0.0 & 0.3 \\
\hline
\end{tabular}

A suitable statistical method as independent sample t-test was also performed to consider the existence of any statistical difference between research variables in terms of gender. As Figure 1 shows, there is an apparent difference between men and women in mean scores. Hence, we applied independent sample t-test to examine whether these differences are statistically significant or not. As can be seen from Table 3, there is no significant difference between males and females in previous experience, education, attitude, subjective norms, behavioral control and entrepreneurial intention $(p>0.05)$.

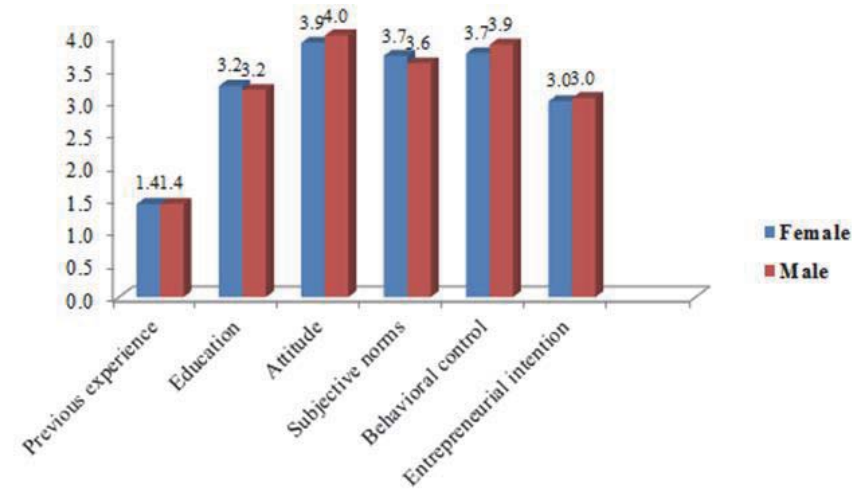

Figure 1: Comparison of Means of Research Variables by Gender

Table 3: Summary of t-test Result for Level of Research Variables by Gender

\begin{tabular}{|c|c|c|c|c|c|c|c|c|c|c|}
\hline & & \multicolumn{9}{|c|}{$\begin{array}{l}\text { Levene's Test } \\
\text { for Equality of } \\
\text { Variances }\end{array}$} \\
\hline & & \multirow[t]{2}{*}{$\mathrm{F}$} & \multirow[t]{2}{*}{ Sig. } & \multirow[t]{2}{*}{$\mathrm{t}$} & \multirow[t]{2}{*}{ Df } & \multirow[t]{2}{*}{$\begin{array}{l}\text { Sig. (2- } \\
\text { tailed) }\end{array}$} & \multirow[t]{2}{*}{$\begin{array}{c}\text { Mean } \\
\text { Difference }\end{array}$} & \multirow[t]{2}{*}{$\begin{array}{l}\text { Std. Error } \\
\text { Difference }\end{array}$} & \multicolumn{2}{|c|}{$\begin{array}{l}95 \% \text { Confidence } \\
\text { Interval of the } \\
\text { Difference }\end{array}$} \\
\hline & & & & & & & & & Lower & Upper \\
\hline Previous & Equal variances assumed & .05 & .823 & -.01 & 378 & .992 & .00 & .06 & -.13 & .13 \\
\hline Experience & Equal variances not assumed & & & -.01 & 377.34 & .992 & .00 & .06 & -.13 & .13 \\
\hline \multirow{2}{*}{ Education } & Equal variances assumed & 3.11 & .080 & .61 & 148 & .545 & .06 & .10 & -.13 & .25 \\
\hline & Equal variances not assumed & & & .60 & 139.22 & .549 & .06 & .10 & -.13 & .25 \\
\hline \multirow{2}{*}{ Attitude } & Equal variances assumed & 1.52 & .219 & -.99 & 198 & .324 & -.11 & .11 & -.33 & .11 \\
\hline & Equal variances not assumed & & & -.99 & 193.45 & .325 & -.11 & .11 & -.33 & .11 \\
\hline \multirow{2}{*}{$\begin{array}{l}\text { Subjective } \\
\text { norms }\end{array}$} & Equal variances assumed & .28 & .598 & 1.25 & 376 & .212 & .12 & .09 & -.07 & .30 \\
\hline & Equal variances not assumed & & & 1.25 & 375.95 & .212 & .12 & .09 & -.07 & .30 \\
\hline \multirow{2}{*}{$\begin{array}{l}\text { Behavioral } \\
\text { control }\end{array}$} & Equal variances assumed & .52 & .471 & -1.85 & 374 & .064 & -.13 & .07 & -.27 & .01 \\
\hline & Equal variances not assumed & & & -1.85 & 369.76 & .065 & -.13 & .07 & -.27 & .01 \\
\hline \multirow{2}{*}{$\begin{array}{l}\text { Entrepreneurial } \\
\text { intention }\end{array}$} & Equal variances assumed & .04 & .839 & -.58 & 293 & .565 & -.05 & .08 & -.22 & .12 \\
\hline & Equal variances not assumed & & & -.58 & 291.72 & .565 & -.05 & .08 & -.22 & .12 \\
\hline
\end{tabular}




\section{Conclusion}

This study aimed to find out the relationship among influential factors of entrepreneurial intention (previous experience, education, attitude, subjective norms, and behavioral control) in terms of gender. The respondents were chosen from postgraduate students in UTM in Malaysia during 2014. In total, the sample $(n=380)$ consisted of 187 males and 193 females who were in their final year of study and were considered appropriate for a decision in entrepreneurship. According to the obtained results, there was no significant difference in entrepreneurial intention between females and males. This finding was not in line with the findings of other studies because gender influences intention for entrepreneurship in some countries like Saudi Arabia (Bandura, 1986).

\section{References}

Bandura, A. (1986). Social foundations of thought and action. Englewood Cliffs, NJ.

Baughn, C. C., Cao, J. S., Le, L. T. M., Lim, V. A., \& Neupert, K. E. (2006). Normative, social and cognitive predictors of entrepreneurial interest in China, Vietnam and the Philippines. Journal of developmental entrepreneurship, 11(01), 57-77.

Brenner, O. C., Pringle, C. D., \& Greenhaus, J. H. (1991). Perceived fulfillment of organizational employment versus entrepreneurship: Work values and 91 career intentions of business college graduates. Journal of Small Business Management, 29(3), 62-74.

Chen, C. C., Greene, P. G., \& Crick, A. (1998). Does entrepreneurial self-efficacy distinguish entrepreneurs from managers? Journal of Business Venturing, 13(4), 295-316. Churchill Jr, G. A., \& lacobucci, D. (2009). Marketing research: methodological foundations: Cengage Learning.

Gartner, W. B. (1985). A conceptual framework for describing the phenomenon of new venture creation. Academy of management review, 10(4), 696-706.

Gupta, V. K., Turban, D. B., Wasti, S. A., \& Sikdar, A. (2009). The role of gender stereotypes in perceptions of entrepreneurs and intentions to become an entrepreneur. Entrepreneurship Theory and Practice, 33(2), 397-417.

Hart, M., \& Harrison, R. (1992). Encouraging enterprise in Northern Ireland: constraints and opportunities. Irish Business and Administrative Research, 13, 104-116.

Ismail, M., Khalid, S. A., Othman, M., Jusoff, H. K., Rahman, N. A., Kassim, K. M., et al. (2009). Entrepreneurial intention among Malaysian undergraduates. International Journal of Business and Management, 4(10), P54.

Kothari, C. (2004). Research methodology: methods and techniques: New Age International.

Lorz, M., Müller, S., \& Volery, T. (2011). Entrepreneurship Education: A Meta Analysis of Impact Studies and Applied Methodologies. Paper presented at the Conference Paper, FGF G-Forum 2011. 